\title{
Antioxidant Evaluation and Chemo-Profiling of Non- conventional Curcuma Species as Conservation of Drug Targeting Molecule
}

Akanksha Jain ( $\square$ akankshanakhat@gmail.com )

Guru Ghasidas University

Parag Jain

Department of Pharmacology, Columbia Institute of Pharmacy, Raipur - 493111, Chhattisgarh, India

\section{Research}

Keywords: C. Longa, C. caesia, C. aromatica, FTIR, antioxidant, curcumin

Posted Date: April 14th, 2020

DOI: https://doi.org/10.21203/rs.3.rs-20453/v1

License: (c) (1) This work is licensed under a Creative Commons Attribution 4.0 International License.

Read Full License 
1 Antioxidant Evaluation and Chemo-Profiling of Non-conventional Curcuma Species as

2 Conservation of Drug Targeting Molecule

3 Akanksha Jain a,*, Parag Jain b

4 a Department of Biotechnology, Guru GhasidasVishwavidyalaya, Bilaspur- 495009,

5 Chhattisgarh, India.

6 b Department of Pharmacology, Columbia Institute of Pharmacy, Raipur - 493111,

7 Chhattisgarh, India.

8

9

10

11

12

13

14

15

16

17

18

$19 *$ Corresponding Author

20 Mrs. Akanksha Jain

21 Department of Biotechnology,

22 Guru Ghasidas Vishwavidyalaya,

23 Bilaspur- 495009, Chhattisgarh, India

24 Telephone No: 9827960143

25 Email ID: akankshanakhat@gmail.com 


\section{Abstract}

27 The objective of the present study was to determine and compare antioxidant activities of 28 different species of Curcuma i.e. Curcuma longa, Curcuma caesia and Curcuma aromatic and 29 their chemoprofiling for conservation of highest yield plants. The functional group analysis of 30 the plants extract were determined by FTIR and structural features of phyto-constituents and 31 Chemo-profiling of ethanol fractions of all targeted Curcuma species showing highest activity 32 were analyzed by GC-MS/MS. Ethanolic extract of $C$. aromatica (ECA) was exhibited to 33 determine high radical scavenging activity against DPPH (92.12\%), lipid Peroxidation (85.13 \pm $340.23 \%)$, nitric oxide scavenging, total reducing power $(700.83 \pm 8.14 \mu \mathrm{g} / \mathrm{mg})$ and ferric reducing 35 power assay. In ABTS + and phosphomolybdate assay Curcuma species showed a significant 36 difference ranging from 67.53 - 98.57\%. Furthermore, the amount of total phenolic and 37 flavonoid content ranged from 3.63 $1.06-545.77 \pm 2.76 \mu \mathrm{g} / \mathrm{mg}$ eq GAE and $21.18-101.29$ $38 \mu \mathrm{g} / \mathrm{mg}$ eq QUE respectively. The results indicated that the ethanolic extracts showed highest in 39 vitro antioxidant activity. It can be conclude from the study that Curcuma species may serve as 40 an important bioresource as an antioxidant drug.

41 Keywords: C. Longa, C. caesia, C. aromatica, FTIR, antioxidant, curcumin. 


\section{Introduction}

54 Plants produce potential sources of natural bioactive compounds such as secondary metabolites, many of which have been subsequently exploited by humans for their beneficial roles in a diverse array of biological functions [1]. Cellular system has developed many endogenous antioxidants such as superoxide dismutase (SOD), catalase, glutathione, glutathione peroxidases and reductase, and nonenzymatic antioxidants like vitamin $\mathrm{E}$ and $\mathrm{C}$ are neutralises the free radicals [2-3]. Many researchers have investigated that the increase levels of antioxidants present in plants are believed to decrease the oxidative damage and its harmful effects [4]. This Curcuma species possess three main diverse phytoconstituents, which have lots of pharmaceutical importance. Chemical constituents of turmeric have been extensively investigated by a long time. Phenols including diarylheptanoids and diarylpentanoids, phenylpropene and terpenoids like monoterpenes, sesquiterpenes, diterpenes, triterpenoids, sterols, flavonoids and some alkaloidal compounds were identified in Curcuma.

Antioxidants, which are the substances to prevent oxidation of other compounds or neutralize free radicals. Curcumin is well known systemic markers of oxidative stress it can significantly reduce the production of reactive oxygen species such as superoxide anions, hydrogen peroxide, and nitrite radical production. Curcumin is considered as a chain-breaking antioxidant. In addition, it is a lipophilic compound, which makes it an efficient scavenger of peroxyl radicals, like vitamin E [5]. Curcumin can be inhibiting the activity of ROS-generating enzymes such as lipoxygenase/cyclooxygenase and xanthine hydrogenase/oxidase [6] to modulate the activity of GSH, catalase, and SOD enzymes due to the neutralization of free radicals [7-8].

Approximately, 100 species of rhizomatous herbs belong to genus Curcuma, family Zingiberaceae are widely distributed in tropical and subtropical regions of the world and mostly cultivated in Asian countries, out of these Turmeric (C. longa Linn), black turmeric (C. caesia Roxb.) and wild turmeric (C. aromatica Salisb.) have high traditional importance. C. longa is termed as "Indian Saffron" because of its golden color. C. longa is the most common traditional drug of Indian and Chinese medicines used as anti-inflammatory, wound healing antibacterial, antifungal, anticancer, antioxidant, anti-HIV, immunomodulatory activities, relieve colic and chest pain, and menstrual difficulties [9]. The effects of C. longa are ascribed to the presence of diarylheptanoid compounds collectively known as curcuminoids, which includes curcumin, demethoxycurcumin, and bisdemethoxycurcumin [10]. Effects of curcumin are mediated through 
84 the regulation of various transcription factors growth factors, inflammatory cytokines, and 85 protein kinases.

86 C. longa is a well-known species of Curcuma; several researches have performed for this plant

87 but the two uncommon species i.e., C. caesia and $C$. aromatica need to explore completely for 88 its biological importance. C. caesia rhizome is a bluish black in color. The inner part of the rhizome emits a characteristic sweet smell due to the presence of essential oil. In India black turmeric have been used to treat fever, stomach problems, allergic, diarrhea, jaundice, liver ailments, snake bite, heart burn, chronic cough, asthma, inflammation, sprains muscle relaxant, haemorrhoids, leprosy, cancer, epilepsy, fever, wound, vomiting, menstrual disorder anthelmentic, aphrodisiac, and gonorrhoeal discharges [11]. C. aromatica stimulate immunomodulatory properties and enhance the health conditions by arresting ageing. It compounds related an antibacterial activity against various microbial infections. In addition used as a tonic, carminative, in sprains, snakebite, skin eruptions, infections and very efficiently improve complexion since long time ago, promoting blood circulation to remove blood stasis and used as cancer preventive drug [12-14]. Hence, the present study aimed to evaluate the antioxidant property of non-conventional Curcuma species and compare to identify the best one. The aim of this study was to evaluate the antioxidative properties of the various extracts of Curcuma species and find the best extracts, which possesses highest antioxidant potential at last, examine the chemical composition of most prominent extracts by GC-MS/MS.

\section{Materials and methods}

\subsection{Materials and reagents}

Gallic acid, ascorbic acid, potassium ferricyanide (III), DPPH (2,2-diphenyl-1-picryhydrazyl), 2,2'-azino-bis(3-ethylbenzothiazoline)-6 sulphonic acid (ABTS-+), 2,4,6-tripyridyl-s-tiazine (TPTZ), tannic acid, quercetin, aluminium chloride, ferric chloride ( $\left.\mathrm{FeCl}_{3}\right)$, sodium nitroprusside, sulphanilic acid, Napthyl ethylene dianilinedihydro chloride (NEDD), sodium phosphate, ammonium molybdate, streptomycin were purchased from Sigma-Aldrich (USA). FolinCiocalteu's phenol reagent, trichloro acetic acid (TCA), solvents ethanol, methanol, ethyl acetate, chloroform, dichloromethane and acetone were of analytical grade. 


\subsection{Collection, Authentication and Extraction of different species of Curcuma}

The rhizome of Curcuma species; C. longa (Bargaon-CL), C. caesia (Acholi-CC) and C. aromatica (Jamsarar-CA) was collectedfrom different villages of Rajnandgaon district Chhattisgarh, India. It was authenticated by the Department of Botany, Guru Ghasidas Vishwavidyalaya and voucher specimen was deposited in the herbarium of the Institute. The samples were dried and ground to fine powder. The powders were subjected to extraction using different solvents i.e. Chloroform, dichloromethane, acetone, ethyl acetate, methanol and ethanol, successively of increasing polarity by soxhlet extraction unit. The extracts were evaporated to dryness and concentrated using a vacuum evaporator for further use. The dried extract was insoluble in petroleum ether, so the remaining solvent extracts were used for analysis.

\subsection{Determination of polyphenols}

Total polyphenolic content (TPC) of the extracts was determined using Folin Ciocalteau method as described by Singleton VL et al. 1999 with slight modification [15]. Folin Ciocalteau reagent is a heteropoly acid complex formed of orthophosphoric acid and molybdotungustic acid there by producing reduced species having characteristic intense blue color exhibiting absorbance at $738 \mathrm{~nm}$. Briefly, in a test tube containing $0.4 \mathrm{~mL}$ of plant extract (1 mg/mL conc.), $2 \mathrm{~mL}$ of $10 \%$ Folin Ciocalteau's reagent and $1.6 \mathrm{~mL}$ of $20.25 \%$ Sodium carbonate was shaked properly and kept in dark for $2 \mathrm{~h}$. The absorbance was determined using spectrophotometer (UV-1800, Shimadzu, Japan) at $738 \mathrm{~nm}$. TPC was calculated with the help of gallic acid standard curve and expressed as $\mu \mathrm{g} \mathrm{GAE} / \mathrm{mg}$ sample.

\subsection{Total flavonol Content}

The total flavonol content was determined according to the aluminium chloride $\left(\mathrm{AlCl}_{3}\right)$ method described by Rajan et al. 2011 in which $\mathrm{AlCl}_{3}$ forms acid stable complex with the $\mathrm{C}_{4}$ keto group or $\mathrm{C}_{3}$ or $\mathrm{C}_{5}$ hydroxyl group of flavones and flavonols [16]. In this method, $0.5 \mathrm{~mL}(1 \mathrm{mg} / \mathrm{mL}$ conc.) plant extract was mixed with $1.5 \mathrm{~mL}$ of methanol, $0.1 \mathrm{~mL}$ of $10 \%$ aluminum chloride, 0.1 $\mathrm{mL}$ of $1 \mathrm{M}$ potassium acetate and $2.8 \mathrm{~mL}$ of distilled water. The absorbance was measured at 425 
$\mathrm{nm}$ after $30 \mathrm{~min}$ at room temperature. The total flavonol content was calculated with the standard curve of Quercetin and expressed the value as $\mu \mathrm{g} / \mathrm{mg}$ Quercetin equivalent.

\subsection{Determination of total flavonoids}

Total flavonoids spectrophotometric method was performed according to Dewanto et al. 2002 [17]. In this method, $250 \mu \mathrm{L}$ of extracts $(1 \mathrm{mg} / \mathrm{mL})$ was mixed with $1.25 \mathrm{~mL}$ of distilled water and $75 \mu \mathrm{L}$ of $5 \% \mathrm{NaNO}_{2}$ solution followed by addition of $150 \mu \mathrm{L}$ of $10 \% \mathrm{AlCl}_{3}$ solution after 5 min. Further, $500 \mu \mathrm{L}$ of $1 \mathrm{M} \mathrm{NaOH}$ and $275 \mu \mathrm{L}$ of distilled water were added to the mixture after 6 min. The solution was mixed well and the absorbance was read at $510 \mathrm{~nm}$. Flavonoids content was calculated with the calibration curve of Quercetin and results were expressed as $\mu \mathrm{g}$ of Quercetin Equivalents per mg of extract (QUEs).

\subsection{Total reducing power assay}

The total reducing power (TRP) of plant extract was determined according to the method of Priya et al., 2012 [18]. Extracts of Curcuma rhizome $1 \mathrm{mg} / \mathrm{mL}$ were mixed with $2.5 \mathrm{~mL}$ of $0.2 \mathrm{M}$ sodium phosphate buffer ( $\mathrm{pH}$ 6.6) and $2.5 \mathrm{~mL}$ of potassium ferricyanide (1\%). The mixture was incubated at $50^{\circ} \mathrm{C}$ for $20 \mathrm{~min}$ followed by addition of $2.5 \mathrm{~mL}$ of $10 \%$ TCA (trichloro acetic acid) and then mixture was centrifuged at $3000 \mathrm{rpm}$ for $10 \mathrm{~min}$. The supernatant $(2.5 \mathrm{~mL})$ was mixed with distilled water $(2.5 \mathrm{~mL})$ and $0.5 \mathrm{~mL}$ of ferric chloride $(0.1 \%)$ and then absorbance was measured at $700 \mathrm{~nm}$. Gallic acid standard curve was used to calculate the TRP of plant extracts. Higher absorbance of the reaction mixture indicates greater reducing power.

\subsection{DPPH radial Scavenging Activity}

The DPPH free radical scavenging assay was performed by the method of Williams et al. 1995, and Aadil et al. 2014, with minor modifications [19-20]. The stock solution of DPPH was prepared by $12 \mathrm{mg}$ DPPH in $50 \mathrm{~mL}$ methanol and the working solution was diluted by mixing 15 $\mathrm{mL}$ stock solution with $45 \mathrm{~mL}$ methanol to obtain an absorbance of $1.1 \pm 0.05$ at $517 \mathrm{~nm}$ (control). A volume of $2800 \mu \mathrm{L}$ aliquot of this solution was mixed with $200 \mu \mathrm{L}$ of $500 \mu \mathrm{g} / \mathrm{mL}$ of plant extracts. The reaction mixture was mixed thoroughly and incubated in dark for $2 \mathrm{~h}$ at room temperature. The absorbance was measured at $517 \mathrm{~nm}$, taking ascorbic acid as standard. The scavenging activity was calculated by the formula as follows:

$$
\text { Scavenging activity }(\%)=\frac{\left(A_{c}-A_{s}\right)}{A_{c}} \times 100
$$


172 Where Ac was the absorbance of the control and A was the absorbance of sample

\section{2.8. FRAP (Ferric reducing power assay)}

174 Ferric reducing power assay of Benzie and Strain, 1996 with minor modification was used to 175 check the antioxidant property of rhizome extracts of Curcuma [21]. The stock solutions of 300 $\mathrm{mM}$ acetate buffer (pH 3.6), $10 \mathrm{mM}$ TPTZ (2,4,6-tripyridyl-s-triazine) solution in $40 \mathrm{mM} \mathrm{HCl}$ and $20 \mathrm{mM}$ anhydrous $\mathrm{FeCl}_{3}$ solutions were prepared. The working solution was freshly prepared by mixing 10:1:1 ratio of acetate buffer, TPTZ and $\mathrm{FeCl}_{3}$, respectively. Plant extracts, $200 \mu \mathrm{L}$ $(500 \mu \mathrm{g} / \mathrm{mL})$ were allowed to react with $2800 \mu \mathrm{L}$ of the FRAP solution for 30 min in dark. Absorbance of colored product (Ferrous tripyridyltriazine complex) was taken at $593 \mathrm{~nm}$ and result was expressed in terms of $\mu \mathrm{M}$ of ascorbic acid.

\subsection{ABTS·+ radial scavenging activity}

The ABTS + assay was performed according to method of Arnao et al. 2001 with some modifications [22]. The ABTS + radical was produced by reacting $7.4 \mathrm{mM}$ ABTS + stock solution with $2.6 \mathrm{mM}$ potassium persulfate and allowing the mixture to stand in dark at $4^{\circ} \mathrm{C}$ for 12-16 h before use. A volume of $1 \mathrm{~mL}$ ABTS + solution was diluted with $50 \mathrm{~mL}$ methanol to A $734=0.7$. Plant extracts $200 \mu \mathrm{L}(500 \mu \mathrm{g} / \mathrm{mL})$ were allowed to react with $2800 \mu \mathrm{L}$ of the ABTS + solution for $2 \mathrm{~h}$ in dark. The absorbance was taken at $734 \mathrm{~nm}$ using tannic acid as standard.

$$
\text { ABTS scavenging activity } \%=\frac{\left(\mathrm{A}_{c}-\mathrm{As}_{\mathrm{s}}\right)}{\mathrm{Ac}_{\mathrm{c}}} \times 100
$$

Where,Ac was the absorbance of the control and As was the absorbance of sample.

\subsection{Nitric oxide scavenging assay}

The free radical scavenging activity was measured by a nitric oxide assay, adopted from Garrat DC, 1964 with minor modification [23]. The reaction mixture containing the plant extracts in $500 \mu \mathrm{l}(1 \mathrm{mg} / \mathrm{mL})$, sodium nitroprusside $(10 \mathrm{mM}, 2 \mathrm{~mL})$ and phosphate buffer saline (PBS, $\mathrm{pH}$ $7.4500 \mu \mathrm{l})$ was incubated at $25^{\circ} \mathrm{C}$ for $150 \mathrm{~min}$. After incubation, $0.5 \mathrm{~mL}$ of reaction mixture from each reaction vessel was separately taken to which $1.0 \mathrm{~mL}$ sulphanilic acid was added and allowed to stand for $5 \mathrm{~min}$ followed by addition of $1.0 \mathrm{~mL}$ of Napthyl ethylene dianilinedihydro chloride (NEDD) then incubated for $30 \mathrm{~min}$ at $25^{\circ} \mathrm{C}$. A pink colored chromophore was formed in 
diffused light. The absorbance of the solution was measured at $540 \mathrm{~nm}$ against the corresponding blank.

\subsection{Phosphomolybdate assay for evaluation of antioxidant capacity}

To check the antioxidant activity of plant extracts, phosphomolybdate assay given by Prieto et al. 1999 and Aadil et al. 2014 was performed [24, 20]. An aliquot of $200 \mu \mathrm{L}$ of plant extracts $(1.0 \mathrm{mg} / \mathrm{mL})$ were mixed with $1.0 \mathrm{~mL}$ of test reagent $(0.6 \mathrm{M}$ sulfuric acid, $28 \mathrm{mM}$ sodium phosphate and $4 \mathrm{mM}$ ammonium molybdate). The tubes were incubated in a water bath at $70^{\circ} \mathrm{C}$ for $90 \mathrm{~min}$. Samples were cooled at ambient temperature and the absorbance was measured against a blank at $695 \mathrm{~nm}$. Antioxidant activity of each sample was expressed in terms of ascorbic acid equivalent to $\mathrm{mM} / 100 \mathrm{mg}$ of sample.

\subsection{Lipid peroxidation by TBA assay}

This method was adopted from Cunn A et al. 2007 [25]. Lipid peroxidation is based on the reaction of a chromogenic reagent, N-methyl-2-phenylindole (R1), with MDA and 4hydroxyalkenals at $45^{\circ} \mathrm{C}$ One molecule of either MDA or 4-hydroxyalkenal reacts with two molecules of reagent R1 to yield a stable chromophore with maximal absorbance at $532 \mathrm{~nm}$. The plant extracts in $0.5 \mathrm{~mL}$ volume $(1.0 \mathrm{mg} / \mathrm{mL})$ were taken in vial followed by addition of $0.5 \mathrm{~mL}$ homogenate of chicken liver prepared in ice cold $0.15 \mathrm{M} \mathrm{KCl}$. Further, $100 \mu 1$ of $0.2 \mathrm{mM} \mathrm{FeCl}_{3}$ was added in the mixture and incubated at $37^{\circ} \mathrm{C}$ for 30 min then $2.0 \mathrm{~mL}(0.25 \mathrm{~N})$ ice cold $\mathrm{HCl}$ containing $15 \%$ TCA, $0.38 \%$ TBA, and $0.5 \%$ BHT were added and heated at $80^{\circ} \mathrm{C}$ for $60 \mathrm{~min}$. The absorbance was measured at $532 \mathrm{~nm}$.

$$
\text { Inhibition of lipid peroxidation }(\%)=\frac{1-\text { sample OD }}{\text { blank OD }} \times 100
$$

\subsection{UV-visible spectral analysis}

UV-visible spectroscopy is the most commonly used technique for the determination of curcumin and curcuminoids like compounds. In order to check the purity and preliminary characterization of phyto-constituents, absorption spectra were recorded by UV-visible spectroscopy (UV-1800, Shimadzu, Japan) from 200 to $500 \mathrm{~nm}$. The extracted phytoconstituents of three targeted Curcuma samples were dissolved in their respective solvents (1 $\mu \mathrm{g} / \mathrm{mL}$ ) that were used for extraction before measuring the absorbance. 


\subsection{FTIR analysis}

FTIR spectra for plant extracts of Curcuma species were obtained between 4000 and $500 \mathrm{~cm}-1$ with a resolution at $4 \mathrm{~cm}-1$. Spectra including standard were recorded using Thermo fisher scientific, OMNIC-9 FTIR spectrophotometer. Extracts of all three Curcuma species (1 mg) were mixed with $100 \mathrm{mg} \mathrm{KBr}$ and properly grounded before analysis.

\subsection{GC-MS/MS analysis of most active extract}

On the basis of primary screening the extracts showing highest antioxidant activity i.e, $C$. longa (ECL), C. caesia (ECC), C. aromatica (ECA) were selected for GC-MS/MS analysis. For sample derivatization $50 \mathrm{mg}$ of concentrated ethanol extracts were redissolved in $200 \mu \mathrm{l}$ of respective solvent vortexed properly and filtered through $0.22 \mathrm{~mm}$ filter, then added $100 \mu \mathrm{BSA}+\mathrm{TMCS}$ and incubated at $80^{\circ} \mathrm{C}$ for 30 minute.

Instrumentation and chromatographic conditions for GC-MS/MS analysis was carried out on a GCMS-QP2010 Ultra, USA, coupled with a mass selective detector (MSD). For the GCMS/MS analysis the samples were injected in split less mode in a column HP5 phenyl methyl siloxane $[25 \mu \mathrm{m}$ (film thickness) $\times 320 \mu \mathrm{m}$ (internal diameter) $\times 30 \mathrm{~m}$ (length of column) $]$ The gas chromatograph was interfaced to a mass spectrometer instrument employing the following conditions viz. Column Oven Temp. :70 ${ }^{\circ} \mathrm{C}$ Injection Temp. :260 $\mathrm{C}$, Injection Mode: Splitless Sampling Time: 1 min. Start Time: 6 min, end Time: 49.98min, Start m/z: 40.00 End m/z: 650.00 .

Identification of putative components based on mass spectra of GC/MS was done using the NIST/EPA/NIH Mass Spectral Database, with NIST MS search program [National Institute Standard and Technology (NIST), Scientific Instrument services, Inc., NJ, USA]. The mass spectrum of the unknown component was compared with the spectrum of the known components stored in the NIST library. The name, molecular weight, and structure of the components of the test materials were ascertained.

\subsection{Statistical analysis}

The experiments were performed in triplicates. The data were recorded as mean $\pm \mathrm{SD}$ and analyzed by Graph pad prism-5.One way ANOVA was performed by standard procedures. 
Significant differences between means were determined by Dunnett's tests and $\mathrm{p}<0.05$ was regarded as significant and $\mathrm{p}<0.0001$ was very significant.

\section{Results and Discussion}

\subsection{Estimation of total phenol content}

The phenolic compounds acts as an antioxidant and radical scavenging agents by breaking free radical chain reaction through a hydrogen atom donation [26]. The content of total phenolics in each fractions were determined as gallic acid equivalents (GAE) using standard curve equation, y $=0.0067 x+0.095, R^{2}=0.9984$. Significantly, higher $(\mathrm{P}<0.0001)$ TPC was obtained in the ethanolic extract of $C$. longa (ECL) $545.77 \pm 2.76 \mu \mathrm{g} / \mathrm{mg}$ GAE followed by $C$. caesia (ECC) $430.77 \pm 1.16$ and $C$. aromatica (ECA) $411.07 \pm 5.36 \mu \mathrm{g} / \mathrm{mg}$ GAE. The range of phenolic content of different extracts varied between $3.63 \pm 1.06$ to $545.77 \pm 2.76 \mu \mathrm{g}$ of GAE per mg of sample. The order of phenolic content was as follows: ECL> MCL>ECC> ECA> MCA> $\mathrm{MCC}>\mathrm{ACL}>\mathrm{ACA}>\mathrm{EaCL}>\mathrm{EaCA}>\mathrm{DCL}>\mathrm{CCL}>\mathrm{EaCC}>\mathrm{ACC}>\mathrm{DCA}>\mathrm{DCC}>\mathrm{CCC}>\mathrm{CCA}$ (Table 1). The key role of phenolic compounds as scavengers of free radicals has emphasized in several literatures [27]. Plants produce many phenolic antioxidants due to their secondary metabolic activity. The antioxidant activity plays an important role in chelating transitional metals and scavenging free radicals [28]. The above results indicated that the phenolic content was high in polar extracts of all the three species of Curcuma. This confirms the fundamental role of polar phenolics in evaluation of free radical scavenging. The total antioxidant activities of the non-polar extracts may be due to the presence of volatile components. The relationship between phenol content and its antioxidant activity has already reported [29-30].

\subsection{Total flavonols}

Flavonoids are also polyphenolic compounds that are ubiquitous in nature and according to their chemical structure categorized into catechins, anthocyanidins, chalcones, flavonols, flavones, flavanones and isoflavones [31]. The total flavonol content varied from $3.54 \pm 2.69$ to $525.70 \pm 7.69 \mu \mathrm{g} / \mathrm{mg}$ QUE. Maximum flavonol content was found in the acetone extract of $C$. aromatica as shown in Table 1. 


\subsection{Total flavonoids}

Flavonoids play significant role as scavengers of various oxidizing species i.e. superoxide anion, hydroxyl radical or peroxy radicals, they also act as quenchers of singlet oxygen. Therefore, many plants containing flavonoid attributed as an antioxidants [32]. The pharmacological activities of flavonoids were closely related to their functional group. Moreover, flavonoids may exert their cell structure protection through a variety of mechanisms. One of their potent effects may be through their ability to increase levels of glutathione, a powerful antioxidant [33]. The total flavonoids content of Curcuma species ranging from18.14 \pm $2.61 \mu \mathrm{g} / \mathrm{mg}$ QUE to $101.29 \pm 1.07 \mu \mathrm{g} / \mathrm{mg}$ QUE. Highest flavonoids content was found in the methanolic extract of $C$. longa followed by ethyl acetate extract of $C$. aromatica (Table 1). Similar result was reported previously that $C$. longa possess high flavonoid content as compare to $C$. caesia [34]. Extracts with polar solvents have a higher flavonoid content compared to extracts with non-polar solvents. In general, the antioxidant activity of Curcuma is due to the presence of flavones, isoflavones, flavonoids and carotenoids [35]. In present study, flavonoid content of $C$. aromatica and $C$. longa was high therefore it exhibited maximum antibacterial as well as antioxidant activity compared to $C$. caesia.

\subsection{Total reducing power assay}

The reducing capacity of compound serves as a significant indicator of its potential antioxidant activity [36]. It is measure as the transformation of $\mathrm{Fe}_{3}+$ to $\mathrm{Fe}_{2}+$ in presence of antioxidant compound [37]. The total reducing power of all plant extracts (Table 2) were evaluated and compared with the standard gallic acid. The highest reducing power was recorded in ethanolic extract of $C$. aromatica $(700.83 \pm 8.14 \mu \mathrm{g} / \mathrm{mg}$ gallic acid equivalent) and lowest with chloroform extract of $C$. aromatica $(25.83 \pm 5.51 \mu \mathrm{g} / \mathrm{mg}$ gallic acid equivalent). $C$. aromatica showed highest reducing power activity compared to other two species. It has reported that $C$. longa possess significant antioxidant activity [38]. However, in this study we have found other two species of Curcuma that possess antioxidant potential to scavenge the free radicals i.e. $C$. caesia and $C$. aromatica. The reducing power of Curcuma is generally associated with the presence of reductones, which have been shown to exert antioxidant activity by breaking the free radical chain by donating a hydrogen atom [39].

\subsection{DPPH radical scavenging activity}


DPPH is a stable free radical and widely used to estimate the free radical scavenging activity of antioxidants. DPPH interact with antioxidants, either transfer of e- or hydrogen atoms to DPPH, therefore neutralize the free radicals and color of reaction mixture of DPPH changes from purple to yellow [40]. DPPH radical scavenging activity of all the organic solvent extracts of rhizome of $C$. longa, $C$. caesia and $C$. aromatica exhibited good scavenging activity ranging from $31.80 \%$ to $92.12 \%$ as shown in Table 2 . The radical scavenging activity of the extracts was equivalent to ascorbic acid, which was used as standard. The ethanolic extract of $C$. aromatica exhibited highest scavenging activity (92.12\%) among all the extracts of three species with

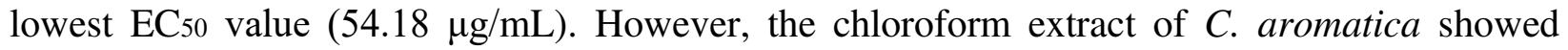
lowest scavenging activity (32.80\%) and highest EC50 $(153.8 \mu \mathrm{g} / \mathrm{mL})$. It is known that lower EC50 value indicates higher antioxidant potential. Comparatively, polar extracts exhibited stronger affinity to give $\mathrm{H}$ - ion to DPPH and neutralize than non-polar extracts. Lowest to highest EC50 value was ranged from $54.18 \mu \mathrm{g} / \mathrm{mL}$ to $153.8 \mu \mathrm{g} / \mathrm{mL}$. C. longa and C. caesia scavenging activity is lower in some extent as compared to $C$. aromatica, extracts activity support the FTIR data due to $\mathrm{C}=\mathrm{OH}$, ketone or $\mathrm{O}-\mathrm{H}$ groups appeared in FTIR spectrum. The entire functional groups present in the FTIR spectra provide stability to the compound and possess great potential to scavenge the antioxidants. It has reported methanolic extract of $C$. longa showed strong antioxidant activity against the DPPH radical with percentage inhibition in the range of 86-92\% [41]. The antioxidant activity in DPPH assay (86.91\%) in ethanolic fraction of C. caesia reported by Devi et al is much similar to the present study [42].

\subsection{FRAP (ferric reducing power assay)}

Antioxidant compounds reduce the ferric tripydyltriazine (Fe III TPTZ) complex to ferrous form and produce intense blue color, which can be measure at $593 \mathrm{~nm}$. Different plant extracts exhibited varying antioxidant potential expressed in terms of $\mu \mathrm{M}$ as showed in (Table 2). FRAP activity was considerably varied from $58.75 \pm 15.6$ to $809.16 \pm 10.4 \mu \mathrm{M}$. The highest FRAP value exhibited in ethanolic extract of $C$. aromatica $(809.16 \pm 10.4 \mu \mathrm{M})$ and lowest in the chloroform extract of $C$. caesia $(58.75 \pm 15.6 \mu \mathrm{M})$. All the values were significant $(\mathrm{P}<0.0001)$ as compared to highest FRAP value. The order of FRAP value of different solvent extracts was: $\mathrm{ECA}>\mathrm{ECC}>\mathrm{EaCA}>\mathrm{MCA}>\mathrm{ECL}>\mathrm{EaCC}>\mathrm{ACA}>\mathrm{ACL}>\mathrm{MCC}>\mathrm{MCL}>\mathrm{EaCL}>\mathrm{DCL}>\mathrm{CCL}>$ $\mathrm{DCC}>\mathrm{DCA}>\mathrm{ACC}>\mathrm{CCA}>\mathrm{CCC}$. All the extracts of $C$. aromatica exhibited great potential to reduce the ferric complex to ferrous form in comparison to $C$. longa and $C$. caesia extracts. 
Similarly, the polar extract showed highest activity compared to non-polar extracts. Literature revealed that the rhizome oil of Curcuma species contains antioxidant compounds, which reduce the ferric complex to ferrous form [43]

\subsection{ABTS + radical scavenging assay}

ABTS + forms a relatively stable free radical, which decolorizes in its non-radical form [44]. The scavenging of ABTS + radical cation, a blue green chromogen produced by a reaction between ABTS + and potassium per sulphate, which is converted to colorless ABTS $+{ }_{+}$in the presence of antioxidant reductant and quantified in terms of inhibition percentage [45]. The ABTS ++ decolorization assay of all the extracts of Curcuma species (Table 2) showed significant difference to each other and exhibited an inhibition range of $67.53 \%$ to $98.57 \%$. Tannic acid was used as a standard showed EC50- $12.05 \pm 0.38 \mu \mathrm{g} / \mathrm{mL}$. C. longa ethyl acetate extract showed lowest $\mathrm{EC}_{50} 50.79 \mu \mathrm{g} / \mathrm{mL}$ and highest $\mathrm{EC}_{50}$ was exhibited by methanolic extract of $C$. aromatica. C. longa extracts exhibited great potential to decolorize the ABTS + radical as compare to $C$. aromatica and $C$. caesia. The $\mathrm{EC}_{50}$ value of different plant extracts were ranged from 50.79 $\mu \mathrm{g} / \mathrm{mL}$ to $72.26 \mu \mathrm{g} / \mathrm{mL}$, ethyl acetate extract of C. longa and C. aromatica showed much similar antioxidant potential in ABTS + radical. The order of scavenging potential EC50 value of all the plant extracts was as follows: $\mathrm{EaCL}<\mathrm{EaCA}<\mathrm{ECL}<\mathrm{DCL}<\mathrm{MCL}<\mathrm{ACL}<\mathrm{MCC}<\mathrm{DCC}<\mathrm{EaCC}<$ $\mathrm{CCL}<\mathrm{ACA}<\mathrm{DCA}<\mathrm{CCC}<\mathrm{ECC}<\mathrm{ACC}<\mathrm{ECA}<\mathrm{CCA}<\mathrm{MCA}$. Curcumin is an effective ABTS + radical scavenger in a concentration dependent manner, scavenging effect of curcumin on ABTS + at the concentration of $45 \mu \mathrm{g} / \mathrm{mL}$ [46]. Results of recent studies also supported ABTS + scavenging potential of Curcuma extracts.

\subsection{Nitric oxide scavenging assay}

Nitric oxide interacts with oxygen to nitrite ions, which is measured at $540 \mathrm{~nm}$ absorbance on spectroscopy. It is generated from sodium nitroprusside in aqueous medium at physiological $\mathrm{pH}$. Nitrous acid generated from nitric oxide forms purple azo dye that reflect its extent of scavenging with decrease in the amount of nitrous acid.

Nitric oxide radical plays multiple roles in a variety of biological processes, which includes as an effector molecule, neuronal messenger, vasodilator, antimicrobial agent, etc. [47]. Curcumin and curcuminoids present in Curcuma species reduced the amount of nitrite formed by the reaction between oxygen and nitric oxide generated from sodium nitroprusside and scavenge 
the free radicals [48]. The nitric oxide scavenging activity was highest in ethanolic extract of $C$. aromatica i.e. $85.71 \%$ and minimum scavenging activity was observed in the methanolic extract of $C$. aromatica (MJA-13\%). Curcumin was used as a standard and its value to scavenge NO was $162.96 \pm 9.81 \mu \mathrm{g}$. Ethanol, acetone and ethyl acetate extract of all the three species of Curcuma showed higher scavenging activity. The EC50 value of NO assay ranged from $116.70 \pm 0.76 \mu \mathrm{g}$ to $678.70 \pm 10.51 \mu \mathrm{g} / \mathrm{mL}$ (Table 2). The EC50 value or order of activity was as follows: ECA > $\mathrm{DCL}>\mathrm{ACL}>\mathrm{EaCA}>\mathrm{CCL}>\mathrm{CCA}>\mathrm{ACA}>\mathrm{CCC}>\mathrm{MCL}>\mathrm{ACC}>\mathrm{ECL}>\mathrm{DCC}>\mathrm{EaCC}>\mathrm{EaCA}>$ $\mathrm{MCC}>\mathrm{ECC}>\mathrm{EaCL}>\mathrm{MCA}$.

\subsection{Phosphomolybdate assay for evaluation of antioxidant capacity}

Reduction of molybdenum (VI) to molybdenum (V) by the antioxidants and the subsequent formation of a green phosphate/Mo (V) complex at acidic $\mathrm{pH}$ show a maximum absorbance at $695 \mathrm{~nm}$ [24]. Table 2 represents varying phosphomolybdate activity of different plant extracts of all the Curcuma species. Methanolic extract of $C$. aromatica exhibited the highest antioxidant power $(271.3 \pm 0.95) \mu \mathrm{g} / 500 \mu \mathrm{g}$ eq to ascorbic acid while lowest antioxidant effect was showed chloroform extract of $C$. aromatica. Methanolic fractions of all the three species of Curcuma showed the highest antioxidant capacity in phosphomolybdate (PM) assay. Based on the results the order of antioxidant capacity of plant extracts was MCA > MCL> MCC> DCA > ECL> $\mathrm{ECC}>\mathrm{CCC}>\mathrm{DCC}>\mathrm{EaCC}>\mathrm{ACA}>\mathrm{EaCA}>\mathrm{ECA}>\mathrm{ACL}>\mathrm{CCL}>\mathrm{DCL}>\mathrm{EaCL}>\mathrm{ACC}>\mathrm{CCA}$. The reports indicate that the antioxidant capacity of $C$. caesia is better than Curcuma amada in phosphomolybdate assay where its value range from 2457.33 and $4534.33 \mathrm{mM} / 100 \mathrm{mg}$ AAE (Reenu J et al, 2015).

\subsection{Lipid peroxidation by TBA assay}

Lipid peroxidation (LPO) is used as an indicator of oxidative stress in cells and tissues. LPO is measured by thiobarbituric acid reactive substances (TBARS) method. It is a well-established method for assessment of cellular injury in plant and animals. The decomposition of lipid peroxides produces several reactive compounds. The measurement of malondialdehyde (MDA) and 4-hydroxyalkenals (HAE) generates from polyunsaturated fatty acid peroxides are indicators of lipid peroxidation [49].

MDA is a marker of oxidative stress [50]. In this study, the potential of all extracted samples of Curcuma species was measured to inhibit the lipid peroxidation in chicken liver 
homogenate induced by the $\mathrm{FeCl}_{2}-\mathrm{H}_{2} \mathrm{O}_{2}$ system. Table 2 shows varying range of inhibition potential of all the extracts of Curcuma. Highest LPX inhibition was found in ethanolic extract of C. aromatica $(85.13 \pm 0.23 \%)$ and lesser extent in chloroform extract of C. caesia (26.18 \pm $0.50 \%$ ). Ethanol and dichloromethane extract of all the three species showed great LPX inhibition and protected cell damage at $85.13 \pm 0.23 \%$ and most of the extract showed greater than $70 \%$ inhibition. The result supported that turmeric as a natural antioxidant can be used to prevent the oxidative deterioration of fat containing food systems or reactive oxygen species mediated tissue damage in biological systems [18].

\subsection{Characterization of Curcuma extracts}

\subsubsection{Spectral analysis}

The UV visible spectra of all the plant extracts of three targeted Curcuma species is shown in Fig. 1. The characteristic peaks of different extracts were observed in the range of 230-400 nm. C. longa extracts absorption spectra in range between $230-425 \mathrm{~nm}$ and the maximum absorption shown at 412-425 nm, similar to curcumin which confirms presence of curcumin in C. longa extracts. For curcumin identification C. longa showed absorption EaCL at (A412nm- 0.361), ACL (A414nm - 2.115), ECL (A412nm - 2.407) likewise. C. caesia and Curcuma aromatica fractions showed varying spectrum as compare to $C$. longa extracts and in this case, spectrum is compared to camphor, present in those species. Most of the absorption of $C$. caesia extracts has ranged from 260-300 nm, much more similar to camphor. Ethyl acetate extract of $C$. caesia have showed maximum absorption at $276 \mathrm{~nm}$ and $C$. aromatica $(\mathrm{EaCA})$ at $289 \mathrm{~nm}$.

\subsubsection{FTIR analysis of plant extracts}

FTIR spectra of all the successive extracts of Curcuma species showed typical bands and variations corresponding to different functional groups (Fig. 2). Results revealed variations in band intensities of different extracts of Curcuma species. Functional groups were strongly affected by the extraction methods as well as the type of solvent used. Different intensities for aromatic - $\mathrm{OH}$ groups were found in all the extracts of Curcuma at 3385-3509 cm-1. Methyl $\left(\mathrm{CH}_{3}\right)$ and methylene $\left(-\mathrm{CH}_{2}\right)$ symmetric and assymetric vibration found in-group of curcuminoids were ranging from 2800-3000 cm-1 [51]. C=O stretching of carboxyl and ketone group appeared in all the extracts at 1652-1750 cm-1, aromatic skeletal vibration was found at 
$1500-1600 \mathrm{~cm}-1$. The peaks at $1521-1616 \mathrm{~cm}-1$ associated with ring conjugated $\mathrm{C}=\mathrm{C}$ stretch and benzene ring bending vibration were observed in all the extracts of Curcuma [52]. The stretching peaks at 1360-1576 cm-1 related to $\mathrm{C}=\mathrm{C}$ medium, weak, multiple bands of aromatic ring or aromatic skeleton vibration and $\mathrm{O}-\mathrm{CH}_{3}, \mathrm{C}-\mathrm{H}$ deformation. The vibration mode at $1027-1270 \mathrm{~cm}-1$ related to $\mathrm{C}-\mathrm{C}, \mathrm{C}-\mathrm{O}$ and $\mathrm{C}-\mathrm{N}$ groups observed in different intensities. The vibration modes at 1512-1570 cm-1 and 1340-1379 cm-1 showed N-O stretching of strong or two-band intensity of extracts of Curcuma. The band at $1000-670 \mathrm{~cm}-1$ appeared mainly due to aromatic C-O, C-H, $\mathrm{C}=\mathrm{O}$, alkyl halide.

\subsubsection{GC-MS/MS analysis of active extract}

The amount of phyto-constituents in turmeric rhizomes vary due to different varieties, locations, agroclimatic zones, sources and cultivation condition. GC-MS/MS chromatograms of ECL (Fig. 3), ECC (Fig. 4), ECA (Fig. 5) rhizome extracts of C. longa, C. caesia and C. aromatica respectively, showed various peaks indicating the presence of different compounds in the respective extracts.

GC-MS/MS chemometric profile of ECL illustrated the presence of 40 different compounds (Table 3, Fig. 3). Amongst the identified compounds, n-tetracosanol-1 (12.06\%), 1-hexadecene (11.48\%), 1,6-heptadiene,2-methyl-6-phenyl (10.99\%) were found in major amount, whereas curlone $(3.85 \%)$, turmerone $(2.25 \%)$, Ar-turmerone $(2.03 \%)$, Dodecanol $(0.84 \%)$ etc. were found to be present in trace. ECC illustrated the presence of 34 different compounds, 1-Heneicosanol (19.13\%), n-Tetracosanol-1 (8.07\%), 1-hexadecene (8.94\%), 3-Octadecene, (E)- (6.16\%) were found in major amount, whereas Andrographolide (0.63\%), (-)-(4R,5S,6R)-4,5,6-TRIS-\{[(Tert butyl)dimethylsilyl]oxy fcyclohex- $(0.36 \%), 1,5$-Diphenylhex-3-ene $(0.55 \%)$ etc. identified in minor (Table 4, Fig. 4). Several trace compounds found in ECA were 1-octadecene (12.39\%), nTetracosanol-1 (15.88\%), 1,6-Heptadiene, 2-methyl-6-phenyl- (8.84\%) were found in major amount whereas 1-Eicosanol (3.99), Non-adecyl-pentafluoropropionate (1.66\%), 1(trimethylsilyl) cyclopropanethiol (0.69\%) etc. represented in Table 5 and Fig. 5. The distribution of phytochemical constituents and biological activities of active principles present in different rhizome extracts of Curcuma species is shown in Table 6 and Table 7. 
467 Most of the compounds identified from rhizome extracts of Curcuma were terpenoids, diterpene, 468 triterpene and sesquiterpene. Andrographolide was reported for first time in $C$. Caesia rhizome, 469 which possesses lots of medication. Furthermore, camphor found in C. caesia, turmerone, Ar470 turmerone, beta- turmerone found in C. longa significantly favor the result of Curcuma species 471 due to its high pharmaceutical importance. Antimicrobial property of Cyclo octa siloxane hexa 472 decamethyl reported in previous study [53] proved the high antibacterial response of $C$. 473 aromatica. The compounds identified by GC-MS/MS analysis were found to possess a diverse 474 range of pharmacological actions [54]

475

476 Conclusion

477 The plant extracts of all the Curcuma species exhibited radical scavenging activity in different in 478 vitro assays, therefore, it can be concluded form the study that the selected species of Curcuma 479 posses antioxidant activity. $C$. caesia showed highest in vitro $\alpha$-amylase inhibitor activity might 480 be a good source of antidiabetic drug in future. $C$. aromatica had highest potential to inhibit the 481 growth of bacteria due to its highest flavonoid content. Further studies on non-conventional $C$. 482 caesia and $C$. aromatica as antioxidant, antidiabetic and antibacterial in animal models are 483 required to assess their long-term pharmaceutical benefits.

484

485 List of abbreviations

486 Reactive oxygen species $=$ ROS

487 Butylated hydroxyl toluene $=$ BHT

488 Butylated hydroxyl anisole $=$ BHA

489 Total polyphenolic content $=$ TPC

490 Microbial type culture collection $=$ MTCC

491 2,4,6-tripyridyl-s-tiazine $=$ TPTZ

492 Total reducing power $=\mathrm{TRP}$

493 Ferric reducing power assay $=$ FRAP 
494 Gallic acid equivalents $=$ GAE

495 Malondialdehyde $=$ MDA

496 4-hydroxyalkenals = HAE

497 2,2-diphenyl-1-picryhydrazyl = DPPH

498 2,2'-azino-bis(3-ethylbenzothiazoline)-6 sulphonic acid = ABTS

499 Trichloro acetic acid $=$ TCA

500 Quercetin Equivalents per mg of extract $=$ QUEs

$501 \quad$ Nutrient agar media $=$ NAM

502 Mass selective detector $=$ MSD

503 Phosphomolybdate $=$ PM

$504 \quad$ Ferric chloride $=\mathrm{FeCl}_{3}$

505 Napthyl ethylene dianilinedihydro chloride=NEDD

506 Lipid peroxidation $=$ LPO

507

508 Declaration

509 - Ethics approval and consent to participate - No animals and humans were included in the 510 study.

511 - Consent for publication - Not applicable.

512 - Availability of data and materials - It can be made available on request.

513 - Competing interests - There is no competing interest.

514 - Funding - No funding was received.

515 - Authors' contributions - AK performed laboratory work, PJ drafted the manuscript.

516 - Acknowledgements - Authors are thankful to the Department of Biotechnology, Guru Ghasidas

517 Vishwavidyalaya Bilaspur (A Central University) to provide infrastructure and financial aid.

518 Authors are also thankful to Aditya Biotech lab \& Research Pvt. Ltd, Raipur (C.G.) for providing 
519 the lab facilities and experimental guidance. Authors are also thankful to to National institute of 520 pathology (NIOP) ICMR, New Delhi for GC-MS/MS analysis.

521

\section{References:}

523 1. Balandrin MF, Klocke JA, Wurtele ES, Bollinger WH. Natural plant chemicals: sources of industrial and medicinal materials. Science. 1985; 228, 1154-1160.

2. Ahmad P, Jaleel C.A., Salem M.A., Nabi G., Sharma S. Roles of enzy-matic and nonenzymatic antioxidants in plants during abiotic stress,Crit. Rev. Biotechnol. 2010;30 (3): 161-175.

3. Yu YY, Kumar V, Bennett M. Murine natural killer cells and marrowgraft rejection, Annu. Rev. Immunol. 1992;10 189-213.

4. Bjelakovic G, Nikolova D, Gluud LL. Mortality in randomised trialsof antioxidant supplements for primary and secondary prevention,J. Am. Med. Assoc. 2007;297 842857.

5. Priyadarsini KI, Maity DK, Naik GH, Kumar MS, Unnikrishnan MK, Satav JG, Mohan $\mathrm{H}$. Role of phenolic $\mathrm{O}-\mathrm{H}$ and methylene hydrogen on the free radical reactions and antioxidant activity of curcumin. Free Radic. Biol. Med. 2003;35, 475-484.

6. Lin YG, Kunnumakkara AB, Nair A, Merritt WM, Han LY, Armaiz-Pena GN, Kamat AA, Spannuth WA, Gershenson DM, Lutgendorf SK. Curcumin inhibits tumor growth and angiogenesis in ovarian carcinoma by targeting the nuclear factor-B pathway. Clin. Cancer Res. 2007; 13, 3423-3430.

7. Marchiani A, Rozzo C, Fadda A, Delogu G, Ruzza P. Curcumin and curcumin-like molecules: From spice to drugs. Curr. Med. Chem. 2014;21, 204-222.

8. Susan J, Hewlings ID, Douglas S, Kalman. Curcumin: A Review of Its' Effects on Human Health. Foods. 2017;6(92), 2-11.

9. Aggarwal BB, Sundaram C, Malani N, Ichikawa H. Curcumin: The Indian solid gold, AdvExp Med Biol. 2007;595:1-75. 
10. Inoue $\mathrm{K}$, Nomura $\mathrm{C}$, Ito S, Nagatsu A, Hino T, Oka H. Purification of curcumin, demethoxycurcumin, and bisdemethoxycurcumin by high-speed countercurrent chromatography, J. Agric. Food Chem. 2008;56:9328-9336.

11. Arulmozhi DK, Sridhar N, Veeranjaneyulu A, Arora KS. Preliminary Mechanistic studies on the smooth muscle relaxant effect of hydroacloholic extract of Curcuma caesia. J Herb Pharmacother. 2006;6:3-4.

12. Chopra RN, Nayar SL, Chopra IC. Glossary of Indian Medicinal Plants, CSIR, New Delhi. 1956; 1: 84.

13. Shi JH, Li CZ, Liu DL. Experimental research on the pharmacology of Curcuma aromatica volatile oil. Zhong Yao Tong Bao. 1981;6:36-38.

14. Anonymous. The Wealth of India. A Dictionary of Indian Raw Materials and Industrial Products. NISCOM (CSIR), New Delhi. 2001; 262-264.

15. Singleton VL, Orthofer R, Raventos RM. Analysis of total phenols and other oxidation substrates and antioxidants by means of Folin-Ciocalteau reagent. Method. Enzymol. 1991; 299: 152-178.

16. Rajan S, Gokila M,Jency P, Brindha P, Sujatha RK. Antioxidant and phytochemical properties of aeglemarmelos fruit pulp, Int J of Cur. Pharm. Research. 2011;3(2): 09757066.

17. Dewanto V, Wu X, Adom KK, Liu RH. Thermal processing enhances the nutritional value of tomatoes by increasing total antioxidant activity, Food Chem. 2002;50:30103014.

18. Priya R, Prathapan A, Raghu KG, Menon AN. Chemical composition and In vitroantioxidative potential of essential oil isolated from Curcuma longa L. leaves, Asian Pac J Trop Biomed. 2012; S695-S699.

19. Williams WB, M.E. Cuvelier, C. Berset, Lebensm. Use of a free radical method to evaluate antioxidant activity, Wiss. Technol. 1995;28:25-30. 
20. Aadil KR, Barapatre A, Sahu S, Jha H, Tiwary BN. Free radical scavenging activity and reducing power of Acacia nilotica wood lignin, Int. J. Biol. Macromol. 2014;220-227.

21. Benzie IF, Strain JT. The ferric reducing ability of plasma (FRAP) as a measure of antioxidant power, the FRAP assay, Anal. Biochem. 1996;239:70.

22. Arnao MB, Cano A, Acosta M. The hydrophilic and lipophilic contribution to total antioxidant activity, Food Chem. 2001;73:239-244.

23. Garrat DC. The Quantitative analysis of Drugs. Chapman and Hall Ltd., Japan. 1964; 3:456- 458 .

24. Prieto P, Pineda M, Aguilar M. Spectrophotometric quantitation of antioxidant capacity through the formation of a phosphomolybdenum complex: specific application to the determination of vitamin E, Anal. Biochem. 1999;269:337-341.

25. Cunn A, Singh R, Singh S, Kumar S, Arora S. Evaluation of antioxidant potential of ethyl acetate extract/fractions of Acacia auriculiformis, Food ChemToxicol. 2007;45:1216-1223.

26. Kosem NY, Moongkarndi P. Antioxidant and cytoprotective activities of methanolic extract from Garcinia mangostana, Hulls. Sci. Asia. 2007;33:283-292.

27. Madsen HL, Nielsen BR, Bertelsen G, Skibsted LH. Screening of antioxidative activity of spices: A comparison between assays based on ESR spin trapping and electrochemical measurement of oxygen consumption, Food Chem. 1996;57: 331337.

28. Decker EA. Phenolics: prooxidants or antioxidants, Nutrition Reviews. 1997;55:396-398.

29. Pourmorad F, Hosseinimerhr SJ, Shahabimajol N. Antioxidant activity, Phenol and flavonoid contents of some selected Iranian medicinal plants. Afr. J. Biotechnol. 2006;3:1142-1145.

30. Velavan S, Nagulendran K, Mahesh R, Asean B. In vitro antioxidant activity of Asperagusracemosus root, Pharmaco. Mag. Res. Art. 2007;3:26-33. 
31. Subedi L, Timalsena S, Duwadi P, Thapa R, Paudel A, Parajuli K. Antioxidant activity and phenol and flavonoid contents of eight medicinal plants from Western Nepal, J Tradit Chin Med. 2014;15 34(5): 584-590.

32. Ratty AK, Das NP. Effects of flavonoids on nonenzymatic lipid peroxidation: structureactivity relationship, Biochem Med MetabBiol. 1998; 39(1):69-79.

33. Byrne DJ, Devaraj S, Grundy SM, Jialal I. Comparison of the antioxidant effects of Concord grape juice flavonoids alpha-tocopherol on markers of oxidative stress in healthy adults, Am. J ClinNutr. 2002;76(6) :1367-1374.

34. Sarangthem K, Haokip MJ. Antioxidant activities, phenols and flavonoid contents of Curcuma longa and Curcuma caesia Roxb. found in Manipur, The bioscan. 2012; 7(1):91-93.

35. Ali AS, Bachar SC, Islam MS. Analgesic activity of the rhizomes of Curcuma zedoaria. J Pharm Sci. 2004; 3:1-2.

36. Dizhbite T, Telysheve G, Jurkjane V, Viesturs U. Characterization of the radical scavenging activity of lignins- natural antioxidants, Bioresour. Technol. 2004;95: 309317.

37. Bhalodia NR, Nariya PB, Acharya RN, Shukla VJ. Evaluation of In vitro antioxidant activity of flowers of Cassia fistula Linn, Int J Pharm Tech Res. 2011;3(1):589-599.

38. Choi HY. Antioxidant Activity of Curcuma longa L., Novel Foodstuff. Mol. Cell. Toxicol. 2009;5(3):237-242.

39. Mathew S, Abraham TE. In vitro antioxidant activity and scavenging effects of Cinnamomumverum leaf extract assayed by different methodologies, Food ChemToxicol. 2006; 44(2): 198-206.

40. Archana B, Dasgupta N, De B. In vitro study of antioxidant activity of Syzygiumcumini fruit, Food chem. 2005;90:727-733. 
41. Zaeoung S, Anuchit P, Niwat K. Cytotoxic and free radical scavenging activities of Zingiberaceous rhizomes. Songklanakarin, Journal of Science Technology. 2005;27: 799-812.

42. Devi HP, Mazumder PB, Devi LP. Antioxidant and antimutagenic activity of Curcuma caesia Roxb. rhizome extracts, Toxicol Rep. 2015;2:423-428.

43. Shahwar D, Raza MA, Bukhari S, Bukhari G. Ferric reducing antioxidant power of essential oils extracted from Eucalyptus and Curcuma species Asian Pac J Trop Biomed. 2012;S1633-S1636.

44. Shirwaikar A, Shirwaikar A, Rajendran K. In vitro antioxidant studies on the benzyl tetra tsoquinoline alkaloid berberine, Biol. Pharm. Bull. 2006;29:1906-1910.

45. MacDonald LK, Wood LG, Garg ML. Methodology for the determination of biological antioxidant capacity In vitro: a review, J. Sci. Food Agric. 2006;86:2046-2056.

46. Tuba AK, GülçinÌlhami. Antioxidant and radical scavenging properties of curcumin, ChemBiolInteract. 20081;174:27-37.

47. Hagerman AE, Jones KM, Riedl SG. High molecular weight plant polyphenolics (tannins) as biological antioxidants, J Agric Food Chem. 1998;46:1887 - 1892.

48. Sreejayan, Rao MN (1997) Nitric oxide scavenging by curcuminoids. J Pharm Pharmacol. Jan 49(1):105-7.

49. Yoshikawa T, Naito Y, Kondo M. Free radicals and diseases. In Food and free radicals. Eds., Hiramatsu, M., Yoshukawa, T., Inoue, M. Plenum Press, New York, NY. 1997;1119.

50. Janero DR. Malondialdehyde and thiobarbituric acid reactivity as diagonostic indices of lipid peroxidation and peroxidative tissue injury, Free Radical Biol. Med. 1990; 9: 515540.

51. Rohaeti E, Rafi M, Syafitri UD, Heryanto R. Fourier transform infrared spectroscopy combined with chemometrics for discrimination of Curcuma longa, Curcuma xanthorrhiza and Zingibercassumunar, Spectrochim. Acta A. 2015; 137: 1244-1249. 
649

650

651

652

653

654

655

656

657

658

659

660

661

662

663

664

665

666

667

668

669

670

671

672

68

71

52. Rohman A, Devi S, Ramadhani D, Nugroho A. Analysis of Curcumin in Curcuma longa and Curcuma xanthorriza Using FTIR Spectroscopy and Chemometrics, J. Med. Plants Res. 2015;9 (4) :179-186.

53. Sheeba GD, Viswanathan P. GC-MS Analysis of Phytocomponents in Spermacocearticularis L. f. leaf, Research in Pharmacy. 2014; 4(4):01-07.

54. Tayade AB, Dhar P, Kumar J, Sharma M, Chauhan RS, Chaurasia OP, Srivastava RB. Chemometric Profile of Root Extracts of RhodiolaimbricataEdgew. with Hyphenated Gas Chromatography Mass Spectrometric Technique, Plos One. 2013; 8 (1): e52797

7

8

9

0

63 


\section{Legends to the Figures:}

674 Figure 1 UV visible spectrum of $C$. aromatica, C. caesia and C. longa rhizome extracts

675 Where, $\mathrm{CCA}=$ Chloroform extract of C. aromatica, $\mathrm{DCA}=$ Dichloromethane extract of $C$. aromatica, $676 \mathrm{ACA}=$ Acetone extract of $C$. aromatica, $\mathrm{EaCA}=$ Ethyl acetate extract of $C$. aromatica, $\mathrm{MCA}=\mathrm{Methanol}$ 677 extract of $C$. aromatica, ECA = Ethanol extract of $C$. aromatica, $\mathrm{CCC}=$ Chloroform extract of C. caesia, $678 \mathrm{DCC}=$ Dichloromethane extract of $C$. caesia, $\mathrm{ACC}=$ Acetone extract of $C$. caesia, $\mathrm{EaCC}=$ Ethyl acetate 679 extract of $C$. caesia, $\mathrm{MCC}=$ Methanol extract of $C$. caesia, $\mathrm{ECC}=$ Ethanol extract of $C$. caesia, $\mathrm{CCL}=$ 680 Chloroform extract of C. longa, DCL $=$ Dichloromethane extract of C. longa, ACL $=$ Acetone extract of 681 C. longa, $\mathrm{EaCL}=\mathrm{Ethyl}$ acetate extract of $C$. longa, $\mathrm{MCL}=$ Methanol extract of $C$. longaand $\mathrm{ECL}=$ 682 Ethanol extract of C. longa

Figure 2 FTIR spectra of $C$. aromatica, $C$. caesia and $C$. longarhizome extracts Where, CCA = 685 Chloroform extract of C. aromatica, DCA $=$ Dichloromethane extract of $C$. aromatica, ACA = Acetone extract of $C$. aromatica, EaCA $=$ Ethyl acetate extract of $C$. aromatica, MCA = Methanol extract of $C$. aromatica, $\mathrm{ECA}=$ Ethanol extract of $C$. aromatica, $\mathrm{CCC}=$ Chloroform extract of C. caesia, $\mathrm{DCC}=$ Dichloromethane extract of $C$. caesia, $\mathrm{ACC}=$ Acetone extract of $C$. caesia, $\mathrm{EaCC}=$ Ethyl acetate extract of $C$. caesia, $\mathrm{MCC}=$ Methanol extract of $C$. caesia, $\mathrm{ECC}=$ Ethanol extract of $C$. caesia, $\mathrm{CCL}=$ 690 Chloroform extract of C. longa, DCL $=$ Dichloromethane extract of $C$. longa, ACL = Acetone extract of 691 C. longa, $\mathrm{EaCL}=$ Ethyl acetate extract of $C$. longa, $\mathrm{MCL}=$ Methanol extract of $C$. longa and $\mathrm{ECL}=$ 692 Ethanol extract of C. longa

693 Figure 3 GC- MS/MS chromatogram of ethanolic extract of $C$. longa rhizome

694 Figure 4 GC- MS/MS chromatogram of ethanolic extract of $C$. caesia rhizome

Figure 5 GC- MS/MS chromatogram of ethanolic extract of $C$. aromatica rhizome 


\section{Figures}
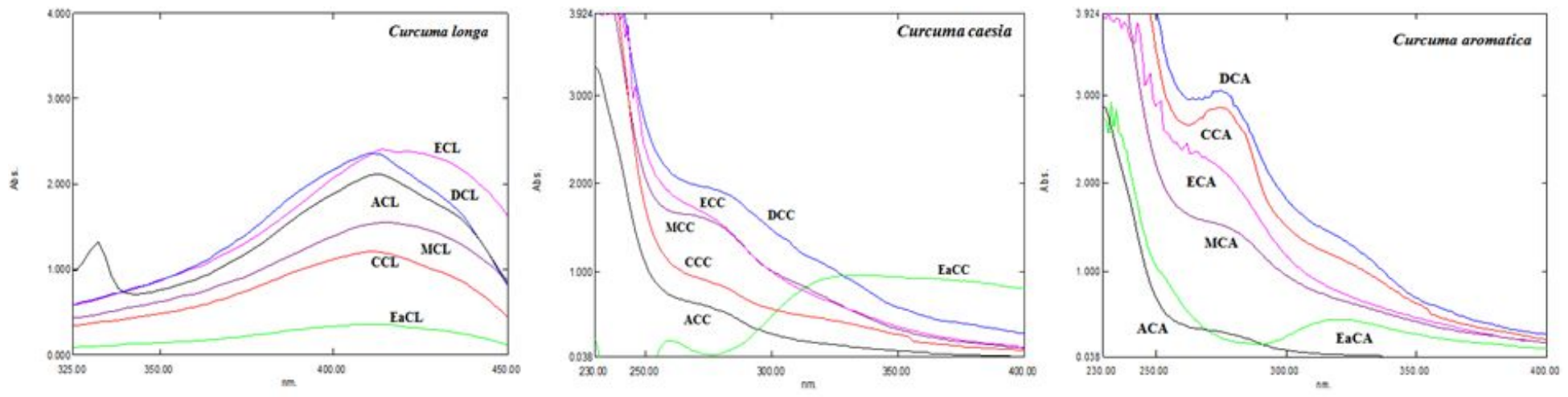

Figure 1

UV visible spectrum of $\mathrm{C}$. aromatica, $\mathrm{C}$. caesia and $\mathrm{C}$. longa rhizome extracts Where, $\mathrm{CCA}=\mathrm{Chloroform}$ extract of $\mathrm{C}$. aromatica, $\mathrm{DCA}=$ Dichloromethane extract of $\mathrm{C}$. aromatica, $\mathrm{ACA}=$ Acetone extract of $\mathrm{C}$. aromatica, EaCA $=$ Ethyl acetate extract of $\mathrm{C}$. aromatica, $\mathrm{MCA}=$ Methanol extract of $\mathrm{C}$. aromatica, ECA = Ethanol extract of $\mathrm{C}$. aromatica, $\mathrm{CCC}=$ Chloroform extract of $\mathrm{C}$. caesia, $\mathrm{DCC}=$ Dichloromethane extract of C. caesia, $\mathrm{ACC}=$ Acetone extract of $\mathrm{C}$. caesia, $\mathrm{EaCC}=$ Ethyl acetate extract of $\mathrm{C}$. caesia, $\mathrm{MCC}=$ Methanol extract of $\mathrm{C}$. caesia, $\mathrm{ECC}=$ Ethanol extract of $\mathrm{C}$. caesia, $\mathrm{CCL}=$ Chloroform extract of $\mathrm{C}$. Ionga, $\mathrm{DCL}=$ Dichloromethane extract of $\mathrm{C}$. longa, $\mathrm{ACL}=$ Acetone extract of $\mathrm{C}$. longa, EaCL = Ethyl acetate extract of $\mathrm{C}$. longa, $\mathrm{MCL}=$ Methanol extract of $\mathrm{C}$. longaand $\mathrm{ECL}=$ Ethanol extract of $\mathrm{C}$. longa 


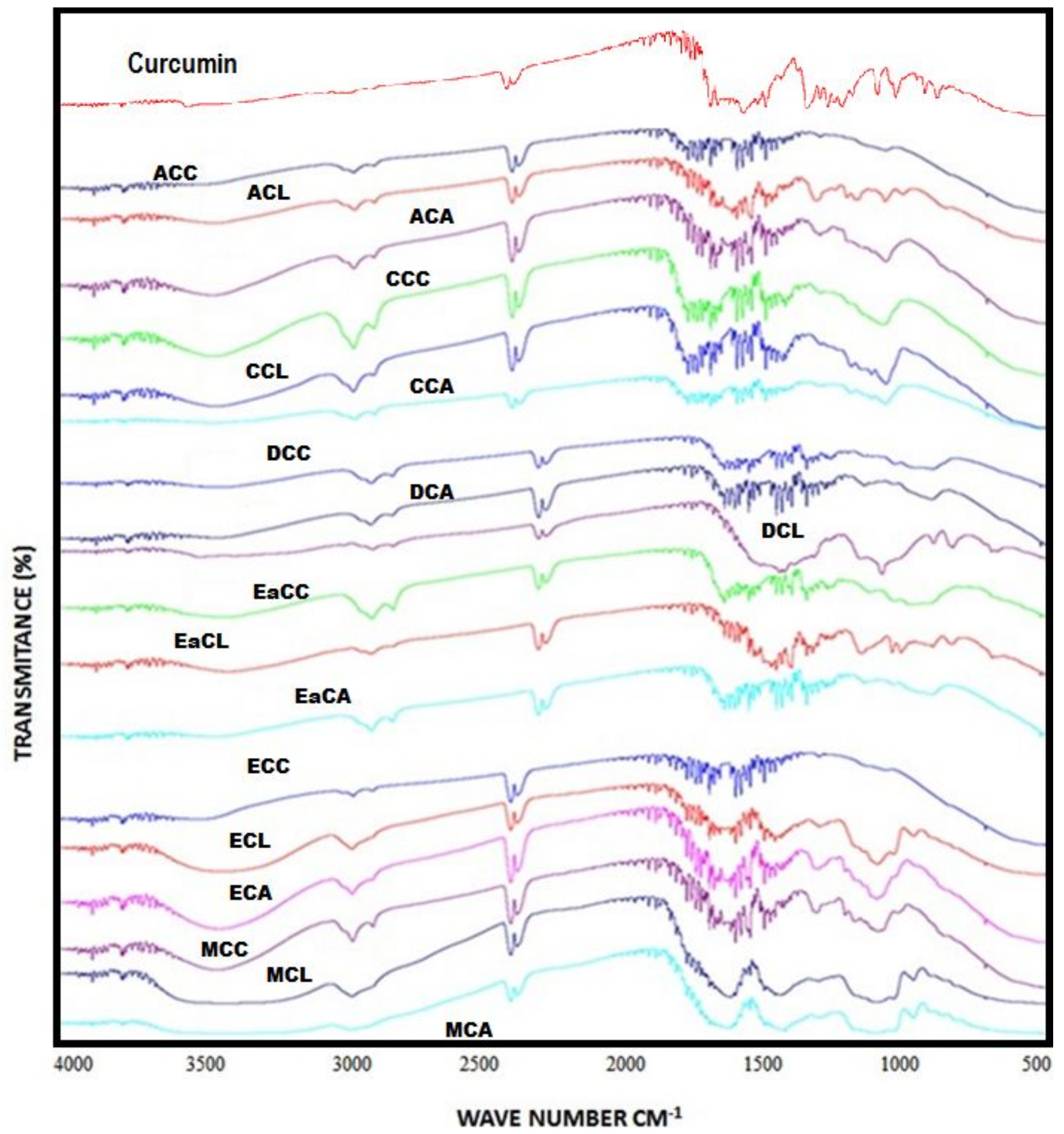

Figure 2

FTIR spectra of C. aromatica, C. caesia and C. Iongarhizome extracts Where, CCA $=$ Chloroform extract of C. aromatica, DCA = Dichloromethane extract of $\mathrm{C}$. aromatica, $\mathrm{ACA}=$ Acetone extract of $\mathrm{C}$. aromatica, $\mathrm{EaCA}=$ Ethyl acetate extract of $\mathrm{C}$. aromatica, $\mathrm{MCA}=$ Methanol extract of $\mathrm{C}$. aromatica, $\mathrm{ECA}=$ Ethanol extract of $\mathrm{C}$. aromatica, $\mathrm{CCC}=$ Chloroform extract of $\mathrm{C}$. caesia, $\mathrm{DCC}=$ Dichloromethane extract of $\mathrm{C}$. caesia, $\mathrm{ACC}=$ Acetone extract of C. caesia, EaCC $=$ Ethyl acetate extract of C. caesia, $\mathrm{MCC}=$ Methanol 
extract of C. caesia, ECC = Ethanol extract of C. caesia, $\mathrm{CCL}=$ Chloroform extract of $\mathrm{C}$. Ionga, $\mathrm{DCL}=$ Dichloromethane extract of $\mathrm{C}$. longa, $\mathrm{ACL}=$ Acetone extract of $\mathrm{C}$. longa, $\mathrm{EaCL}=$ Ethyl acetate extract of $\mathrm{C}$. longa, $\mathrm{MCL}=$ Methanol extract of $\mathrm{C}$. longa and $\mathrm{ECL}=$ Ethanol extract of $\mathrm{C}$. longa

\section{$1,000,000$}

GC-MS/MS CHROMATOGRAME OF ECL

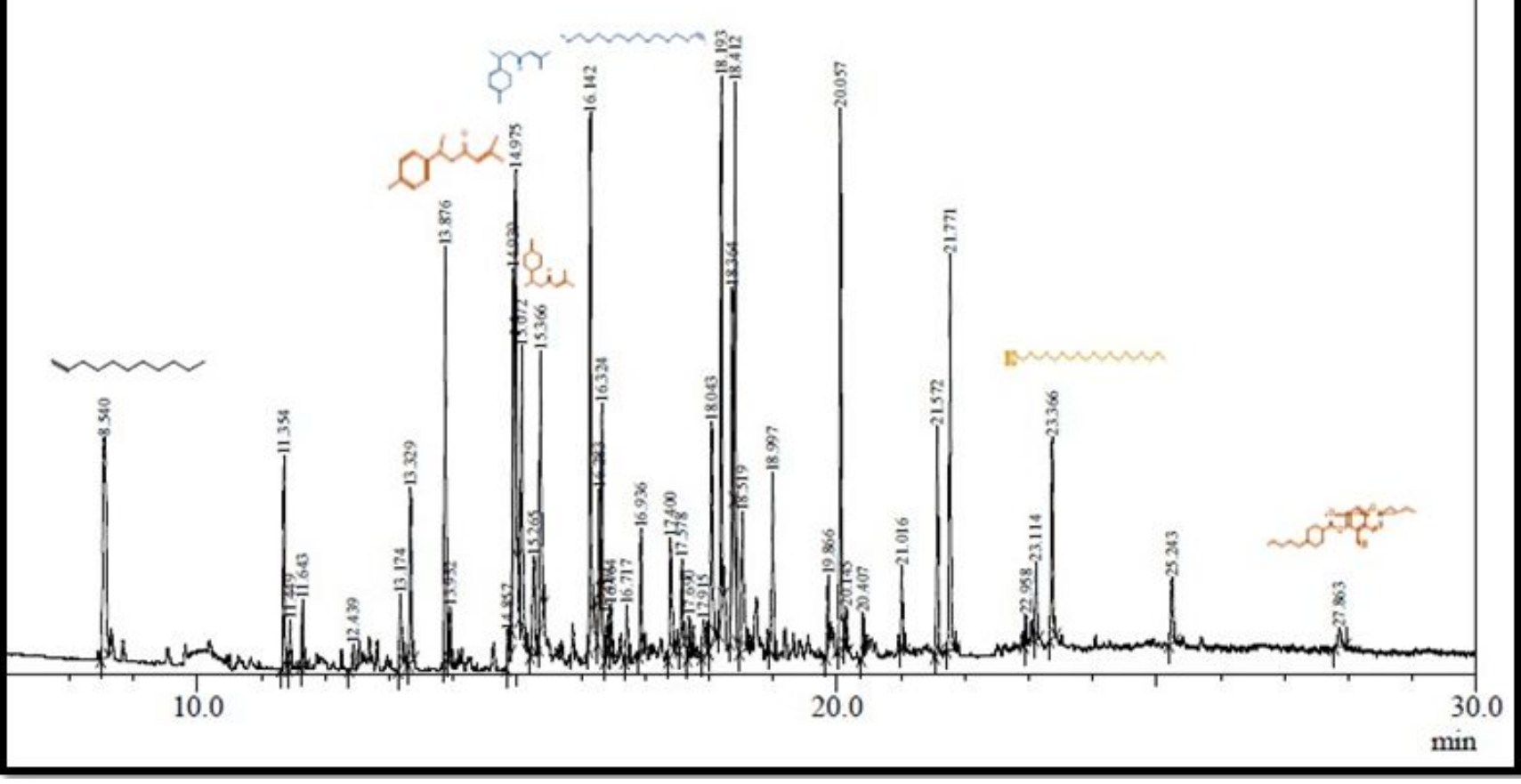

Figure 3

GC- MS/MS chromatogram of ethanolic extract of C. longa rhizome 


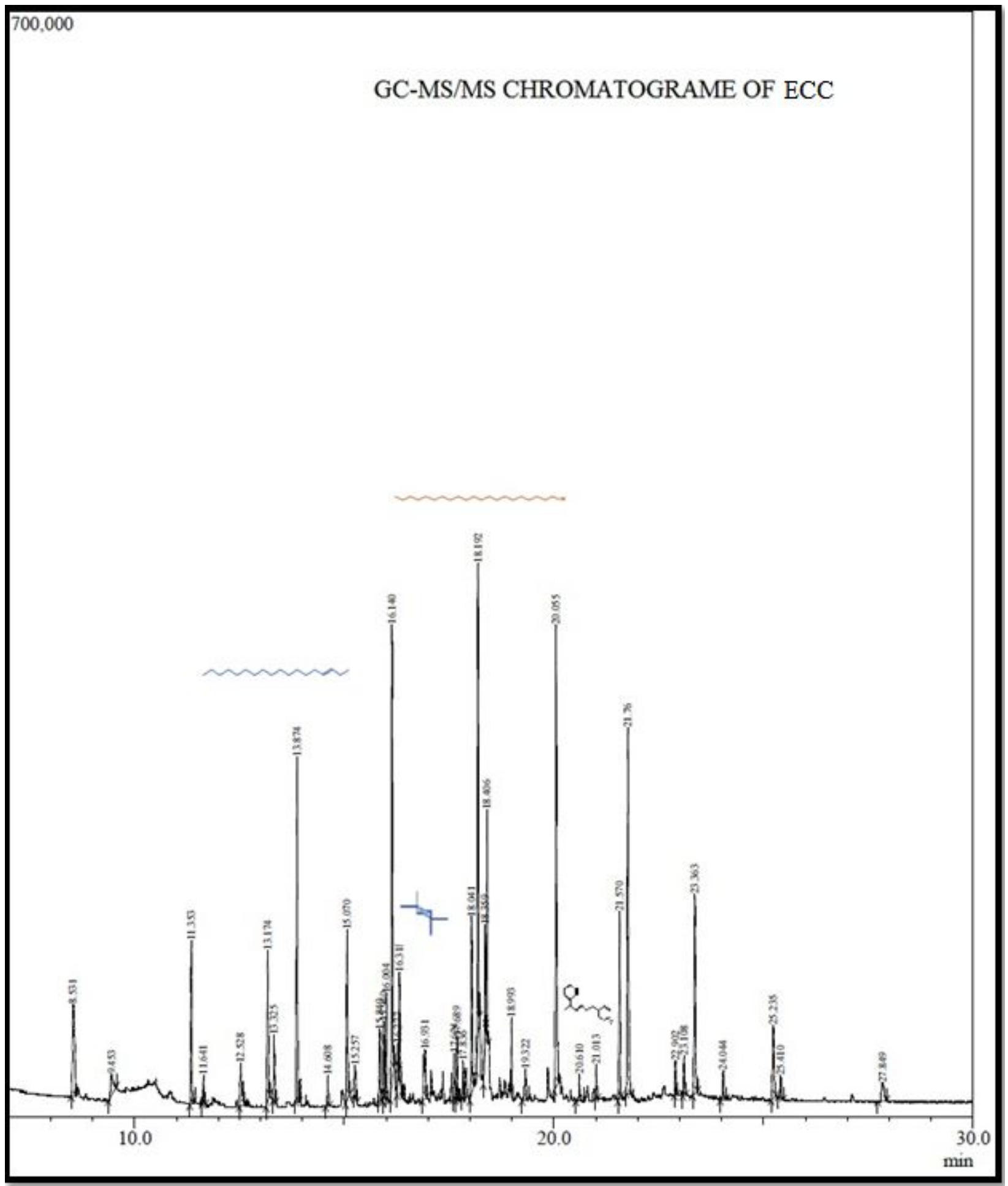

Figure 4

GC-MS/MS chromatogram of ethanolic extract of C. caesia rhizome 


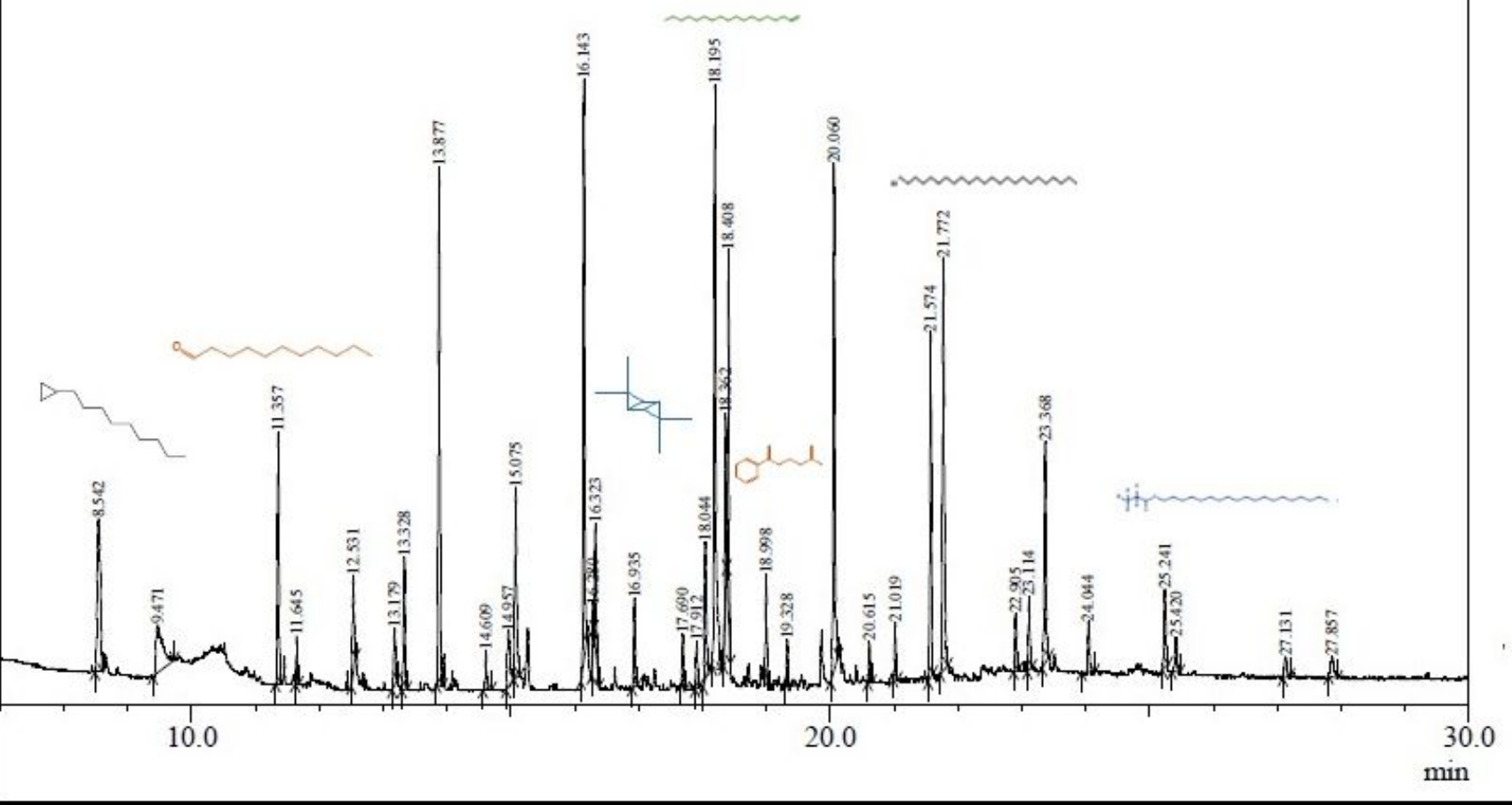

Figure 5

GC- MS/MS chromatogram of ethanolic extract of C. aromatica rhizome

\section{Supplementary Files}

This is a list of supplementary files associated with this preprint. Click to download. 
- Table.docx 